\title{
PERANAN INSENTIF TERHADAP KINERJA KARYAWAN PT HALEYORA POWER RAYON CIKEMBAR KABUPATEN SUKABUMI
}

\author{
Faisal Rizky Sabani $^{1}$, Erry Sunarya ${ }^{2}$ \\ Universitas Muhammadiyah Sukabumi ${ }^{1,2}$ \\ Faisal20@gmail.com ${ }^{1}$
}

\begin{abstract}
ABSTRAK
Tujuan dari penelitian ini adalah untuk mengetahui pengaruh Insentif terhadap Kinerja Karyawan. Metode yang digunakan dalam penelitian ini yaitu menggunakan metode deskritif dan asosiatif. Teknik pengumpulan data yang dilakukan peneliti dalam penelitian ini yaitu melalui observasi, wawancara angket, dokumentasi dan studi kepustakaan. Hasil perhitungan Uji hipotesis $t$ hitung $\geq \mathrm{t}$ abel yaitu 14,071 $\geq 1,997$. Simpulan, terdapat pengaruh yang signifikan antara insentif terhadap kinerja karyawan.
\end{abstract}

Kata Kunci: Insentif, Kinerja Karyawan

\section{ABSTRACT}

The purpose of this study was to determine the effect of incentives on employee performance. The method used in this research is to use descriptive and associative methods. Data collection techniques used by researchers in this study are through observation, questionnaire interviews, documentation and literature studies. The results of the calculation of the hypothesis test $t$ arithmetic ab $t$ abel is $14.071 \geq 1.997$. Conclusion, there is a significant influence between incentives on employee performance.

Keywords: Incentives, Employee Performance

\section{PENDAHULUAN}

Insentif merupakan salah satu perangsang yang diberikan secara sengaja oleh perusahaan apapun jabatannya, dengan tujuan ikut memelihara, memperkuat dan membangun harapan manajer dan karyawan agar dalam diri karyawan timbul semangat kerja yang lebih besar untuk berpartisipasi bagi perusahaan dalam hal peningkatan produktivitas kerja (Candrawati et al., (2013). Maka insentif akan merangsang peningkatan kinerja karyawan, hal ini berarti sangat mendukung pencapaian tujuan perusahaan yang pada akhirnya insentif membawa manfaat bagi kedua pihak bagi karyawan akan meningkatkan prestasi kerja yang berarti akan meningkatkan penghasilan perusahaan, dengan mengacu pada bentuk pemberian insentif yang salah satunya adalah piecework yang merupakan pembayaran yang diukur menurut banyakanya unit atau satuan barang dan jasa yang dihasilkan oleh individu tersebut, 
adapun sistem pemberian insentif yang bisa diberikan perhari, perminggu ataupun perbulan (Rendi, 2015).

Kinerja karyawan dalam sebuah perusahaan yang memiliki kinerja baik dengan etos kerja yang tinggi akan membantu perusahaan untuk dapat memenuhi target perusahaan tersebut dan membantu perusahaan dalam mendapatkan keuntungan. Berbeda dengan kinerja karyawan yang buruk yang dapat merugikan perusahaan tersebut, oleh karena itu perusahaan harus mengelola sumber daya manusia dengan baik agar karyawan dapat bekerja maksimal, tidak ada konflik antara karyawan dengan perusahaan, serta tercapainya kepuasan terhadap kedua belah pihak. Kinerja karyawan sangat perlu adanya penilaian dengan maksud untuk memberikan peluang yang baik maupun buruk yang dilihat dari kinerja karyawan itu sendiri dalam bekerja sehari-hari (Ikbal, Gunair, 2015; Fandy, 2017).

PT Haleyora Power yang tersebar hampir disetiap daerah ini pun berada di wilayah cikembar yang melayani pelayanan teknis (Yantek) dan penagih (Billman) yang tidak bisa dipungkiri menjadi ujung tombak perusahaan untuk mendapatkan pendapatan, ketika kedua unsur ini kinerjanya menurun diindikasikan pendapatan perusahaan pun ikut menurun.

Permasalahan di lapangan bahwa PT Haleyora Power yang menjadi mitra (persero) ketika bekerja harus mengejar target yang telah di ditetapkan oleh perusahaan, dalam melakukan penagihan sering terhambat dengan jauhnya jarak rumah pelanggan dan juga medan yang cukup berat sehingga dalam pelaksanaannya membutuhkan biaya, Biaya tersebut adalah untuk karyawan yang membutuhkan insentif pada tiap bulan nya dalam memenuhi kebutuhan perbulan atau pun memenuhi kebutuhan kesehariannya. Temuan di lapangan setelah penulis mewawancarai salah seorang supervisor menemukan bahwa karyawan PT Haleyora Power (HP) yang menjadi mitra dari (persero) bahwa insentif yang diberikan oleh perusahaan terasa kurang dengan membandingkan dengan jarak dan medan yang ditempuh oleh karyawan ketika bekerja.

Diawali pada bulan april 2 bulan berikutnya di tahun 2018 saldo tunggakan PT Haleyora Power Rayon Cikembar mengalami kenaikan hal ini diduga oleh kinerja karyawan yang tidak sesuai dengan target yang ditentukan, maka dari itu adanya indikasi bahwa kenaikan saldo tunggakan PT Haleyora Power Rayon Cikembar di 
sebabkan oleh menurunnya kinerja karyawan sebagai penagih (Billman) yang di karenakan tidak sesuai nya insentif dengan jarak yang ditempuh oleh karyawan.

\section{KAJIAN TEORI}

Konsep insentif Menurut Handoko (2002) menyatakan bahwa pengertian insentif adalah: "Perangsang yang ditawarkan kepada para karyawan untuk melaksanakan kerja sesuai atau lebih tinggi dari standar-standar yang telah ditetapkan". Sedangkan Pangabean (2002) Insentif adalah kompensasi yang mengaitkan gaji dengan produktivitas, insentif merupakan penghargaan dalam bentuk uang yang diberikan kepada mereka yang dapat bekerja melampaui standar yang telah ditentukan. Relevan dengan itu Hasibuan (2006) menyatakan insentif adalah semua pendapatan yang berbentuk uang, barang langsung atau tidak langsung yang diterima oleh pegawai sebagai imbalan atas jasa yang diberikan atas suatu organisasi atau perusahaan.

Berdasarkan kajian teori dapat disimpulkan bahwa insentif adalah suatu penghargaan dalam bentuk material atau non material yang diberikan oleh pihak pimpinan organisasi perusahaan kepada karyawannya dengan tujuan agar mereka bekerja dengan motivasi yang tinggi dan berprestasi dalam mencapai tujuan - tujuan perusahaan, dengan kata lain pemberian insentif adalah pemberian uang diluar gaji sebagai pengakuan perusahaan terhadap prestasi kerja dan kontribusi karyawannya Alat motivasi yang umum diberikan oleh perusahaan untuk merangsang, memotivasi serta meningkatkan kinerja pegawai adalah insentif (Maziah, 2016).

Mangkuprawira, Hubeis (2007) mengatakan bahwa kinerja adalah hasil dari proses pekerjaan tertentu secara terencana pada waktu dan tempat dari karyawan serta organisasi bersangkutan.

Mangkuprawira, Hubeis (2007) menyebutkan bahwa "kinerja karyawan dipengaruhi oleh faktor intrinsik dan ektrinsik pegawai”. Faktor-faktor intrinsik yang mempengaruhi kinerja pegawai terdiri dari pendidikan, pengalaman, motivasi, kesehatan, usia, keterampilan, emosi dan spiritual.

Borman, Ackerman \& Kubisiak's (1995) dan Motowidlo \& Van scotter (1994) dalam Kappagoda et al., (2014) membagi kinerja dalam 2 dimensi, yaitu kinerja tugas (task performance) dan kinerja kontekstual (contextual performance). 


\section{Kinerja Tugas (Task Performance)}

Menurut Williams \& Karau (1991) dalam sonnentag, Vorlmer \& Spychala (2010) kinerja tugas merupakan kontribusi seorang karyawan terhadapa organisasi berupa perilaku dan tindakan yang sebagaimana telah ditentukan dalam deskripsi pekerjaan. Serupa dengan pernyataan sebelumnnya. Borman \& Motowidlo (1997) dalam Jankingthong \& Rurkkhum (2012) menekankan bahwa kinerja tugas mengacu pada perilaku dan kegiatan yang secara langsung terlibat dan memberikan kontribusi dalam kegiatan inti organisasi. Kinerja tugas dapat diukur menggunakan 3 sub dimensi, antara lain kemampuan dalam menjalankan tugas, efisiensi dan pemecahan masalah.

\section{Kinerja Kontekstual (Contextual Performance)}

Borman \& Motowidlo (1993) dalam ssonnentag, Volmer \& spychala (2010) mendefinisikan kinerja kontekstual sebagai upaya individu yang tidak terkait langsung dengan kegiatan dan fungsi tugas utama mereka dalam organisasi. Kinerja kontekstual tidak secara langsung dengan kegiatan dan fungsi tugas utama mereka dalam organisasi. Kinerja kontekstual tidak secara langsung terlibat atau berkontribusi tehadap kegiatan inti organisasi, namun tetap mendukung sosial, psikologis dan lingkungan organisasi (Jankingthong \& Rurkkhum, 2012). Kinerja kontekstual diukur dengan menggunakan 2 sub dimensi, antara lain kuantitas pekerjaan dan kualitas pekerjaan.

\section{METODE PENELITIAN}

Penelitian ini menggunakan pendekatan manajemen sumberdaya manusia mengenai pengaruh insentif dan kinerja karyawan. Dalam penelitian ini terdapat dua variabel yang dijadikan kawasan penelitian yaitu; insentif (Variabel X) dan kinerja karyawan (Variabel Y) dimana yang dijadikan variabel terikat (Variabel Dependent) adalah Y dan yang dijadikan variabel bebas (Variabel Independent). Metode penelitian yang digunakan untuk menjawab rumusan masalah pertama dan kedua menggunakan metode deskriptif dengan menggunakan pendekatan asosiatif.

Statistik deskriptif adalah statistik yang digunakan untuk menganalisis data dengan cara mendeskripsikan atau menggambarkan data yang telah terkumpul sebagaimana adanya tanpa bermaksud membuat kesimpulan yang berlaku untuk umum atau generelisasi. Berdasarkan hal tersebut dalam penelitian ini penulis bermaksud 
untuk memberikan gambaran kepada pembaca, serta menyampaikan tentang suatu masalah atau suatu keadaan mengenai kinerja PT Haleyora Power atas insentif yang diberikan.

\section{HASIL PENELITIAN}

\section{Hasil Uji Regresi Linier Sederhana}

Analisis regresi linear sederhana adalah hubungan secara linear antara satu variabel independen $(\mathrm{X})$ dengan variabel dependen $(\mathrm{Y})$. Analisis ini untuk mengetahui arah hubungan antara variabel independen dengan variabel dependen apakah positif atau negatif dan untuk memprediksi nilai dari variabel dependen apabila nilai variabel independen mengalami kenaikan atau penurunan. Hasil analisis regresi sederhana dapat dilihat pada tabel berikut ini.

Tabel 1 Regresi Linier Sederhana

\begin{tabular}{|c|c|c|c|c|c|}
\hline \multirow[t]{2}{*}{ Model } & \multicolumn{2}{|c|}{$\begin{array}{l}\text { Unstandardized } \\
\text { Coefficients }\end{array}$} & $\begin{array}{l}\text { Standardized } \\
\text { Coefficients }\end{array}$ & \multirow[t]{2}{*}{$\mathrm{t}$} & \multirow[t]{2}{*}{ Sig. } \\
\hline & B & Std. Error & Beta & & \\
\hline $1 \quad$ (Constant) & 7,979 & ,730 & & 10,934 & ,000 \\
\hline insentif & ,945 & ,067 & ,866 & 14,071 & ,000 \\
\hline
\end{tabular}

$Y=7,979+0,945 \mathrm{X}$. Persamaan regresi tersebut dapat dijelaskan sebagai berikut:

$\mathrm{a}=7,979$ merupakan nilai konstanta, menunjukan bahwa jika insentif adalah 0 , maka kinerja karyawan nilainya sebesar 7,979.

$\mathrm{b}=0,945$ merupakan nilai koefisien menunjukan bahwa setiap kenaikan insentif sebesar 1 point, maka kinerja karyawan akan meningkat sebesar 0,945.

\section{Uji Koefisien Korelasi}

Tabel 2 Uji Koefisien Korelasi

\begin{tabular}{llll} 
Correlations & & & \\
\hline & & insentif & kinerja \\
\hline Insentif & Pearson Correlation & 1 &, $866^{* * *}$ \\
& Sig. (2-tailed) & &, 000 \\
& $\mathrm{~N}$ & 68 & 68 \\
\hline Kinerja & Pearson Correlation &, $866^{* *}$ & 1 \\
& Sig. (2-tailed) &, 000 & \\
& $\mathrm{~N}$ & 68 & 68 \\
\hline$* *$ Correlation &
\end{tabular}

**. Correlation is significant at the 0.01 level (2-tailed). Sumber: Hasil pengelolahan data Spss 2019 
Pada data diatas terlihat korelasi antara pemberian insentif terhadap kinerja karyawan menghasilkan angka 0,866 dan nilai sig 2- (tailed) sebesar 000. Angka tersebut menunjukan angka dibawah atau lebih kecil dari 0,05, maka nilai korelasi tersebut berhubungan positif (+) dan signifikan. Hal ini menunjukan bahwa hubungan searah yang artinya jika insentif diberikan kepada karyawan secara efektif maka kinerja karyawan akan meningkat. Begitupun sebaliknya.

\section{Koefisien Determinasi}

Tabel 3 Koefisien Determinasi

\begin{tabular}{lllll}
\hline \multicolumn{2}{l}{ Model Summary } & & & \\
\hline Model & R & R Square & Adjusted R Square & Std. Error of the Estimate \\
\hline 1 &, $866^{\mathrm{a}}$ &, 750 &, 746 & 1,387 \\
a. Predictors: (Constant), insentif & & \\
\hline
\end{tabular}

Sumber: Hasil pengelolahan data kuisioner 2019

Dari hasil pengelolahan pada tabel diatas dapat diketahui bahwa kontribusi pemberian insentif terhadap kinerja karyawan sebesar 75\% sedangkan sisanya sebesar 93\% dipengaruhi oleh faktor-faktor lain yang tidak ditemukan dalam penelitian ini. Alasan mengapa $\mathrm{R}$ berpengaruh sangat rendah dikarenakan bahwa insentif hanya diberikan kepada karyawan tertentu yang memilili kinerjanya melebihi standar yang ditentukan oleh perusahaan, selain itu, pemberian gajui secara teratur setiap bulan kepada karyawan berpengaruh rendahnya R. Dari hal tersebut banyak faktor lain yang mempengaruhi terutama adalah pemberian gaji pokok karyawan.

\section{Uji Parsial (Uji-t)}

Tabel 4 Uji Parsial (Uji-t)

\begin{tabular}{|c|c|c|c|c|c|}
\hline \multicolumn{6}{|l|}{ Coefficients $^{\mathrm{a}}$} \\
\hline \multirow[t]{2}{*}{ Model } & \multirow{2}{*}{\multicolumn{2}{|c|}{$\begin{array}{l}\text { Unstandardized } \\
\text { Coefficients }\end{array}$}} & Standardized & $\mathrm{t}$ & Sig. \\
\hline & & & Coefficients & & \\
\hline \multirow{2}{*}{$1 \quad \begin{array}{l}\text { (Constant) } \\
\text { insentif }\end{array}$} & 7,979 & ,730 & & 10,934 & ,000 \\
\hline & ,945 & ,067 &, 866 & 14,071 & ,000 \\
\hline \multicolumn{6}{|c|}{ a. Dependent Variable: kinerja } \\
\hline
\end{tabular}


Berdasarkan hasil tabel diatas didapat t hitung sebesar 14,071, dengan derajat kebebasan $(\mathrm{df})=\mathrm{n}-2$. Maka $\mathrm{t}$ tabelnya adalah 1.997. Karena $\mathrm{t}$ hitung $>\mathrm{t}$ tabel dengan tingkat signifikan pada tabel sebesar 0,000 yang artinya 0,000<0,05 maka Ho ditolak dan Ha diterima berarti dapat diketahui bhwa pemberian insentif secara signifikan mempengaruhi kinerja karyawan pada PT Haleyora Power Cikembar Sukabumi pada tingkat standar koefisiennya sebesar 0,886 atau $886 \%$.

\section{PEMBAHASAN}

Korelasi antara pemberian insentif terhadap kinerja karyawan menghasilkan angka 0,866 dan nilai sig 2- (tailed) sebesar 000. Angka tersebut menunjukan angka dibawah atau lebih kecil dari 0,05, maka nilai korelasi tersebut berhubungan positif (+) dan signifikan. Hal ini menunjukan bahwa hubungan searah yang artinya jika insentif diberikan kepada karyawan secara efektif maka kinerja karyawan akan meningkat. Begitupun sebaliknya.

Hasil tabel diatas didapat thitung sebesar 14,071, dengan derajat kebebasan (df) $=\mathrm{n}-2$. Maka $\mathrm{t}$ tabelnya adalah 1.997. Karena $\mathrm{t}$ hitung $>\mathrm{t}$ tabel dengan tingkat signifikan pada tabel sebesar 0,000 yang artinya $0,000<0,05$ maka Ho ditolak dan Ha diterima berarti dapat diketahui bhwa pemberian insentif secara signifikan mempengaruhi kinerja karyawan pada PT Haleyora Power Cikembar Sukabumi pada tingkat standar koefisiennya sebesar 0,886 atau $886 \%$.

Insentif akan merangsang peningkatan kinerja karyawan, hal ini berarti sangat mendukung pencapaian tujuan perusahaan yang pada akhirnya insentif membawa manfaat bagi kedua pihak bagi karyawan akan meningkatkan prestasi kerja yang berarti akan meningkatkan penghasilan perusahaan, dengan mengacu pada bentuk pemberian insentif yang salah satunya adalah piecework yang merupakan pembayaran yang diukur menurut banyakanya unit atau satuan barang dan jasa yang dihasilkan oleh individu tersebut, adapun sistem pemberian insentif yang bisa diberikan perhari, perminggu ataupun perbulan (Rendi, 2015).

Kinerja karyawan dalam sebuah perusahaan yang memiliki kinerja baik dengan etos kerja yang tinggi akan membantu perusahaan untuk dapat memenuhi target perusahaan tersebut dan membantu perusahaan dalam mendapatkan keuntungan. Berbeda dengan kinerja karyawan yang buruk yang dapat merugikan perusahaan 
tersebut, oleh karena itu perusahaan harus mengelola sumber daya manusia dengan baik agar karyawan dapat bekerja maksimal, tidak ada konflik antara karyawan dengan perusahaan, serta tercapainya kepuasan terhadap kedua belah pihak. Kinerja karyawan sangat perlu adanya penilaian dengan maksud untuk memberikan peluang yang baik maupun buruk yang dilihat dari kinerja karyawan itu sendiri dalam bekerja sehari-hari (Ikbal, Gunair, 2015; Fandy, 2017).

\section{SIMPULAN}

Berdasarkan hasil penelitian, pembahasan dan teknik data yang peneliti lakukan mengenai insentif terhadap kinerja karyawan PT Haleyora Power Cikembar Sukabumi. Maka peneliti dapat mengambil kesimpulan sebagai berikut:

1. Insentif kerja yang diberikan kepada karyawan PT Haleyora Power Cikembar Sukabumi dapat dikatakan masih tergolong sedang dikarenakan mendapatkan dari hasil presentase yang didapatkan oleh perusahaan kurang baik.

2. kinerja karyawan yang terjadi di PT Haleyora Power Cikembar Sukabumi sejauh ini memiliki karyawan yang cukup baik, namun dilihat dari kenaikan tunggakan perbulan disebabkan oleh kinerja karyawan yang kurang baik.

3. insentif terhadap kinerja karyawan pada PT Haleyora Power Cikembar Sukabumi memiliki pengaruh signifikan, maka dapat disimpulkan setelah pengujian hipotesis.

\section{DAFTAR PUSTAKA}

Borman, W. C., Ackerman, L. D., \& Kubisiak, U. C. (1995). Development of a Performance Rating Program in Support of Department of Labor Test Validation Research. Cooperative Personnel Services, Sacremento

Candrawati, D. D., Al-Musadieq, M., \& Hakam, S. (2013). Pengaruh Insentif terhadap Kinerja Karyawan (Studi pada Karyawan Duta Catering-Cv Darma Utama Batu) Malang: Fakultas Ilmu Administrasi Universitas Brawijaya Malang

Fandy, G. (2017). Pengaruh Insentif terhadap Kinerja Karyawan dengan Keadilan sebagai Variabel Moderasi pada Pt Lautan Teduh Interniaga. Lampung

Handoko, T., \& Hani, H. (2002). Manajemen Personalia dan Sumber Daya Manusia. Yogyakarta: BPFE

Hasibuan, M. (2006). Manajemen Sumber Daya Manusia: Pengertian Dasar, Pengertian, dan Masalah. Jakarta: PT. Toko Gunung Agung

Ikbal, H. M., \& Gunair, G. (2015). Pengaruh Pemberian Insentif terhadap Kinerja Karyawan Pt. Suraco Jaya Abadi Motor di Masamba Kabupaten Luwu Utara. Masamba : Sekolah Tinggi Ilmu Ekonomi Muhammadiyah Palopo 
Jankingthong, K., \& Rurkkum, S. (2012). Factors Affecting Job Performance: A Review of Literature. Silpakorn University Journal of Social Science, Humanities and Arts, 12(2), 115-127

Kappagoda, S., \& Othman, H. Z. F., \& Alwis, G. D. (2014). Psychological Capital and Job Performance: The Mediating Role of Work Attitudes. Journal of Human Resource and Sustainability Studies

Mangkuprawira, S., \& Hubeis, A. (2007). Manajemen Mutu Sumber Daya Manusia. Bogor: Penerbit Ghalia Indonesia

Maziah, M. (2016). Pengaruh Pemberian Insentif terhadap Kinerja Karyawan pada Pt. Bni Syariah Makassar. Makassar

Motowidlo, S. J., Borman, W. C. \& Schmit, M. J. (1997). A Theory of Individual Differences in Task and Contextual Performance. Human Performance, 10, 71-83. Retrieved from Scientific Research Journal Database

Panggabean, P., \& Mutiara S. (2002). Manajemen Sumber Daya Manusia. Jakarta: Ghalia Indonesia

Rendi, H. (2015). Pengaruh Pemberian Insentif terhadap Kinerja Karyawan Distributor Baterai Yuasa (Kasus Pt. Riau Indotama Abadi Pekanbaru). Riau: Fakultas Ilmu Sosial dan Ilmu Politik Universitas Riau

Sonnentag, S.,Volmer, J., \& Spychala, A. (2010). Job Performance. Los Angeles, California: (Sage Handbook of Organizational behavior, vol.1) 